\title{
Maternal and Neonatal Metabolic Outcomes of Vitamin D Supplementation in Gestational Diabetes Mellitus: A Systematic Review and Meta-Analysis
}

\author{
Fatemeh Jahanjoo Azizeh Farshbaf-Khalili Seyed Kazem Shakouri \\ Neda Dolatkhah \\ Aging Research Institute, Physical Medicine and Rehabilitation Research Center, Tabriz University of Medical Sciences, \\ Tabriz, Iran
}

\section{Keywords}

Vitamin D.Supplementation · Gestational diabetes mellitus · Metabolic outcomes · Meta-analysis · Systematic review

\begin{abstract}
Introduction: Many scientists have revealed the association between vitamin D deficiency and gestational diabetes mellitus (GDM). The purpose of this review was to evaluate the impact of vitamin D supplementation on maternal and neonatal health measures in GDM. Methods: A comprehensive systematic literature search in the electronic databases including Cochrane Central Register of Controlled Trials, MEDLINE (PubMed), Scopus, Web of Sciences, EMBASE, Google Scholar, Clininaltrial.gov, and ProQuest as well as SID, Magiran, Irandoc, and Iranmedex for Persian literature review carried out up to January 2018. All RCTs and quasi-experimental studies that compared vitamin D supplementation with placebo or without supplementation on GDM women were included in this review. Results: Five randomized controlled trials involving 310 women were included in the meta-analysis. There were significant differences in fasting Plasma Glucose (FPG; mean difference [MD] $-12.54,95 \% \mathrm{Cl}-15.03$ to -10.05 ; 3 trials, 223 participants); total cholesterol (TC; MD
\end{abstract}

$-24.77,95 \% \mathrm{Cl}-32.57$ to -16.98 ; 3 trials, 223 participants); low-density lipoprotein (LDL) cholesterol (MD -18.92, 95\% Cl -24.97 to -12.88; 3 trials, 223 participants); high-density lipoprotein (HDL) cholesterol (MD, 3.87, 95\% Cl 1.20-6.55; 3 trials, 223 participants); high sensitivity C-reactive protein (hs-CRP; MD $-1.35,95 \% \mathrm{Cl}-2.41$ to $-0.28 ; 2$ trials, 126 participants); and Newborns' hyperbilirubinemia (OR 0.33, 95\% Cl 0.13-0.80; 2 trials, 129 participants). Conclusions: Supplementation of GDM women with vitamin D may lead to an improvement in FPG, TC, LDL, HDL, hs-CRP serum levels as well as in newborns' hyperbilirubinemia.

๑) 2018 S. Karger AG, Basel

\section{Introduction}

Gestational diabetes mellitus (GDM) contributes to perinatal mortality and morbidity drastically. It is increasing worldwide [1]. GDM is specified as carbohydrate intolerance of different intensity with beginning or first detection in pregnancy that does not fulfill the diagnostic criteria of overt diabetes mellitus [2].

GDM happens when insulin receptors are not able to react sufficiently to manage blood glucose levels because

\section{KARGER}

(C) 2018 S. Karger AG, Basel

E-Mail karger@karger.com

www.karger.com/anm
Neda Dolatkhah, MD, PhD

Aging Research Institute, Physical Medicine and Rehabilitation Research Center

Tabriz University of Medical Sciences, Emam Reza Hospital

Golgasht, Azadi Ave., Tabriz (Iran)

E-Mail neda_dolatkhah@yahoo.com,dolatkhahn@tbzmed.ac.ir 
of hormones produced during pregnancy, such as human placental lactogen, which affects sensitive insulin receptors. This, in turn, affords elevated levels of plasma glucose improperly [3]. Because of the comparability in the fundamental pathophysiology and hazard factors of GDM and diabetes type 2, it is possible that the factors that are useful in the prohibition of type- 2 diabetes mellitus (T2DM) may be favored in the prohibition of GDM too.

Alterations in lifestyle, ranging from dietary habits and physical activity, lead to the management of elevated blood sugar in pregnant subjects [4].

Although suitable nutrition and orderly physical activity have been demonstrated to decrease blood levels of sugar [5, 6], preserving a good lifestyle is not easy [7]. Recently, there has been growing attention in nutritional components and supplements that can help in decreasing blood sugar and improving metabolic profile [8-12].

Vitamin $\mathrm{D}$ is one of the fat-soluble vitamins that is found in 2 compounds, that is, ergocalciferol (D2) and cholecalciferol (D3). Vitamin D plays an essential function in the bone and mineral metabolism. Vitamin D deficiency is a frequent global health dilemma and is the reason for causing osteoporosis and osteomalacia, rickets, and other bone-related disorders [13]. In the most recent decade, researchers perceived that decreased serum 25 -hydroxy vitamin $\mathrm{D}$ levels were related to metabolic diseases like type 1 diabetes, obesity, insulin resistance, cardiovascular diseases, and cancer [14-16].

Preclinical animal models have revealed that vitamin $\mathrm{D}$ is a fundamental factor required for regular insulin secretion [17, 18]. Vitamin D decreases insulin resistance possibly through its impact on calcium and phosphorus homeostasis and through the setting up of the insulin receptor gene [19]. Vitamin D deficiency is recognized to be associated with blood sugar and insulin level change and insulin sensitivity [20].

Vitamin D deficiency is prevalent in pregnancy and evidence demonstrates that vitamin $\mathrm{D}$ results in improved sensitivity to insulin and many scientists have revealed the association between vitamin $\mathrm{D}$ deficiency and GDM [21].

As vitamin $\mathrm{D}$ has a vital task in placental metabolism [22] and metabolic conditions throughout pregnancy [23], the purpose of the present review was to appraise the results from disseminated randomized controlled trials (RCTs) and evaluate the impact of vitamin D supplementation on maternal and neonatal metabolic outcomes in women affected by GDM. We also assessed the hypothesis "Vitamin D supplementation in pregnant women with GDM has beneficial effects." Similar reviews have been published [24, 25]. However, authors aimed to perform it in a much focused way and omit the irrelevant information.

\section{Materials and Methods}

\section{Information Sources and Search Strategy}

The primary aim of our systematic review and meta-analysis was to examine maternal health outcomes of vitamin D supplementation in GDM. The impact of vitamin D supplementation on neonatal health measures was considered a secondary outcome. Two authors (N.D. and A.F.-K.) separately carried out a comprehensive systematic literature search using electronic databases including Cochrane Central Register of Controlled Trials, MEDLINE (PubMed), Scopus, Web of Sciences, EMBASE, Google Scholar, Clininaltrial.gov, Science direct, and ProQuest as well as Scientific Information Database (SID), Magiran, Irandoc, and Iranmedex for Persian literature review based on titles and abstracts up to January 2018. At the same time, 2 authors hand-searched bibliographies of the included studies and reviewed citations for any possible studies for inclusion.

A literature search was performed using following Medical Subject Headings terms and Boolean operators: "vitamin D" OR “25(OH) D” OR “25-hydroxy vitamin D” OR “25-OH-D” AND "GDM" OR "gestational diabetes" OR "diabetes pregnancy" OR "diabetic mother" OR "insulin gestation".

Two authors conducted searching in terms of publishing new articles related to the purpose of this study after the initial search via:

1. Monthly searches of Cochrane Database and Cochran Central Register of Controlled Trials (CENTRAL);

2. Weekly searches of EMBASE;

3. Weekly searches of Medline;

4. Weekly searches of Scopus, Google Scholar, ProQuest, and Science Direct;

5. Weekly searches of Persian databases such as SID, Magiran, and IranMedex.

Endnote software (Thomas Reuters, Philadelphia, PA) was employed to manage the findings of the search as recognized by the mentioned strategies.

\section{Eligibility Criteria}

To recognize eligible studies, 3 independent researchers (N.D., A.F.-K., and S.K.S.) carried out a primary screening of titles and abstracts, and then evaluated the full text of appropriate studies in detail. The collected articles independently screened to prevent duplication, and the titles and abstracts were reviewed for inclusion by 3 review authors (N.D., A.F.-K., and S.K.S.). Then they obtained the full text for citations judged as potentially eligible by at least one of the reviewers. The disagreements between 2 reviewers were resolved through discussion with the fourth author.

The present study has been designed according to the guidelines in Cochrane Collaboration handbook [26] and Preferred Reporting Items for Systematic Reviews and Meta-Analyses: the PRISMA statement $[27,28]$. The PICOS format (participants, interventions, comparators, outcomes, study design) was followed to determine the study eligibility criteria (Table 1). 
Table 1. PICOS criteria for inclusion and exclusion of studies

\begin{tabular}{ll}
\hline Parameter & Determined criteria for present study \\
\hline Participants & $\begin{array}{l}\text { Pregnant women with GDM (normal or high risk for GDM) irrespective of the } \\
\text { gestational age }\end{array}$ \\
\hline Intervention & $\begin{array}{l}\text { Vitamin D supplementation without restrictions regarding dose (e.g., high, low), } \\
\text { dosing interval (e.g., daily, weekly), and administration route (e.g., oral, IM) }\end{array}$ \\
\hline Comparator & Placebo/without supplementation \\
\hline Outcomes & Any beneficial effect of supplementation on maternal health outcomes \\
\hline Study design & RCTs \\
\hline
\end{tabular}

\section{Inclusion and Exclusion Criteria}

All RCTs and quasi-experimental studies that compared vitamin D supplementation with placebo or without supplementation in GDM pregnant women were included in this review. All included studies were in English or Persian languages and their publication status (published, unpublished, or in press) was not taken into consideration. These selected studies evaluated the effects of vitamin D supplementation on various maternal and neonatal indices such as fasting plasma glucose (FPG), insulin, homeostasis Model Assessment-Insulin Resistance (HOMA-IR), homeostatic model assessment of beta-cell function (HOMA-B), quantitative insulin sensitivity check index (QUICKI), triglyceride (TG), total cholesterol (TC), high-density lipoprotein (HDL) cholesterol, low-density lipoprotein (LDL) cholesterol, total chol/ HDL ratio, HDL-cholesterol ratio, high sensitivity C-reactive protein (hs-CRP), hemoglobin A1C (HbA1C), hemoglobin A1c\% (HbA1c\%), plasma total antioxidant capacity, plasma total glutathione (GSH), serum calcium (Serum calcium), body mass index (BMI), and glucose tolerance test in pregnant women with GDM, as well as Newborns' hypoglycemia and hyperbilirubinemia.

Vitamin D could be administered during pregnancy in forms of vitamin D2 or D3, ordered at any dose, by any route (oral or intramuscular), and at any regularity - "regular" in which supplementation was provided at least 3 times in a regular/recurrent way (such as daily, weekly, monthly) and "bolus" dose programs in which the supplement was offered only once or twice.

Review articles, semi-experimental studies without a control arm, animal studies, study protocols, letters, and trials in which vitamin $\mathrm{D}$ were investigated in combination with other nutrients or drugs that may affect GDM were not incorporated. Finally, fulltext review of collected studies indicated that a total of $5 \mathrm{RCT}$ met all the inclusion criteria and could be retained for meta-analysis: Asemi et al. [29], Asemi et al. [30], Valizadeh et al. [31], Li et al. [32], and Yazdchi et al. [33] (Figure 1).

\section{Quality and risk-of-bias assessment}

The 3 authors (N.D., A.F.-K., and S.K.S.) independently evaluated methodological quality and risk of bias with the Cochrane Collaboration's tool for assessing the risk of bias [18]. The items considered included random sequence generation, allocation concealment, blinding, intention to treat or per protocol analysis, incomplete data assessment, selective outcome report, controlling dietary intake, and other potential bias (free of expertise bias). Disagreements between review authors were resolved by the fourth author (F.J.). Each criterion was assessed with 3 potential responses: low risk of bias; high risk of bias; or unclear risk of bias.

\section{Random Sequence Generation (Selection Bias)}

The 3 terms "high risk," "low risk," and "unknown risk" were used to determine the bias in generating a random sequence. If a random component such as random numbers table, throwing a 6 -sided dice, tossing a coin was described in the sequence generation process, low risk was reported for the selection bias. If the investigators used a non-random component, such as admission date, file number, patient's or doctor's opinion, or laboratory results in the sequence generation process, a high risk of bias was reported for selection bias. In the cases where the sequence generation process was not specified, the selection bias was reported as an unknown risk.

\section{Allocation Concealment (Selection Bias)}

The 3 terms "high risk," "low risk," and "unknown risk" were used to determine the bias in the allocation concealment. The risk of selection bias in terms of allocation concealment was considered to be at low risk if the investigators use methods such as sequentially numbered, sealed, opaque, sealed envelopes or numbered drug containers or central allocation (i.e., telephone, web-based). There was a high risk in selection bias if the allocation was not based on these methods. There was an unknown risk of bias in terms of allocation concealment if the information was not provided.

Blinding of Participants and Personnel (Performance Bias)

The 3 terms "high risk," "low risk," and "unknown risk" were used to determine the bias in the blinding of participants and personnel.

The bias of performance was considered to be at low risk if the researchers and participants were blinded in a way that it was unlikely that the blinding could have been broken. If the blinding was not performed, the bias of performance was considered to be at high risk. If no information was provided on blinding, the term unknown risk was used.

Blinding of Outcome Assessment (Detection Bias)

The 3 terms "high risk," "low risk" and "unknown risk" were used to determine the bias in the outcome assessment. The bias of detection was considered to be at low risk if the blinding of the 
Fig. 1. Diagram for the search and selection

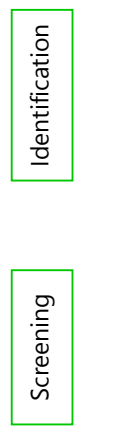

Records identified through database searching $(n=7,835)$

Additional records identified through other sources $(n=0)$

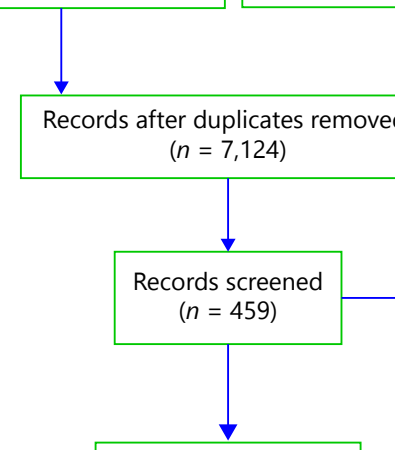

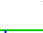

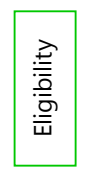

Full text articles assessed for eligibility $(n=19)$

Records excluded ( $n=440)$ Not only 25(OH)D $(n=17)$ Preventing or preventing and treating GDM $(n=40)$

$\rightarrow$ Not RCT or quasi eperimental study $(n=305)$

Not human study $(n=47)$

Not pregnancy and surveying T1DM or T2DM $(n=31)$

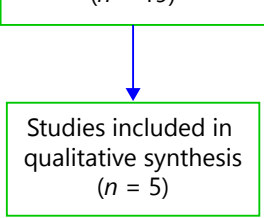
process of articles considered in this review.

outcome assessment was ensured and high risk if was not ensured. If no information was provided, the term "unknown risk" was used.

Incomplete Outcome Data (Attrition Bias)

The 3 terms "high risk," "low risk," and "unknown risk" were used to determine the attrition bias. The attrition bias was considered to be at low risk if the groups were balanced and high risk if the groups were not balanced. If no information was provided, the term unknown risk was used.

Selective Reporting (Reporting Bias)

The 3 terms "high risk," "low risk," and "unknown risk" were used to determine the reporting bias. The reporting bias was considered to be at low risk if pre-specified outcomes have been reported and if the study protocol was available. In the cases where the pre-specified outcomes have not been reported or the study protocol was no available, the reporting bias was considered to be at high risk. In cases where the explanation was not specific enough, the risk was considered to be at unknown risk.

\section{Risk of Bias in Articles}

Random Sequence Generation (Selection Bias)

In the studies done by Asemi et al. [29], Asemi et al. [30], and by Yazdchi et al. [33], where the investigators used a computer random number generator for randomizing, the risk of selection bias was low. In the studies done by Li et al. [32] and Valizadeh et al. [31] where the investigators used a block randomization method, the risk of selection bias was low.
Allocation Concealment (Selection Bias)

In the studies done by Asemi et al. [29], Asemi et al. [30], and by Yazdchi et al. [33], the investigators stated that randomized allocation sequence was generated by a trained midwife and the participants were assigned to the intervention groups by the same person. Because the midwife could possibly foresee assignments, there was a high risk of selection bias in the term of allocation concealment. The study of Li et al. [32] due to the use of a permuted block randomization method, which was stratified according to their baseline, had a low risk from the view of this bias. The study of Valizadeh et al. [31] because of concealing the random allocation papers in sequentially-numbered envelopes had a low risk from the view of allocation concealment.

Blinding of Participants and Personnel (Performance Bias)

In the studies of Asemi et al. [29] and Yazdchi et al. [33], because there was no explanation about blinding, the risk of performance bias was rated unknown. In the studies of Asemi et al. [30] and Li et al. [32] as the blinding of investigator and participants was ensured, the performance bias was rated low risk. In the study by Valizadeh et al. [31] in 2016, the risk was high because there was no blinding.

\section{Blinding of Outcome Assessment (Detection Bias)}

In the studies of Asemi et al. [29] and Yazdchi et al. [33], the risk of detection bias was unknown. In the studies of Asemi et al. [30] and Li et al. [32], the risk of detection bias was low because this study was double blinded. In the study by Valizadeh et al. [31], because there was no blinding, this risk was high. 
Fig. 2. Methodological quality graph: review authors judgments about each methodological quality item presented as percentages across all included studies.

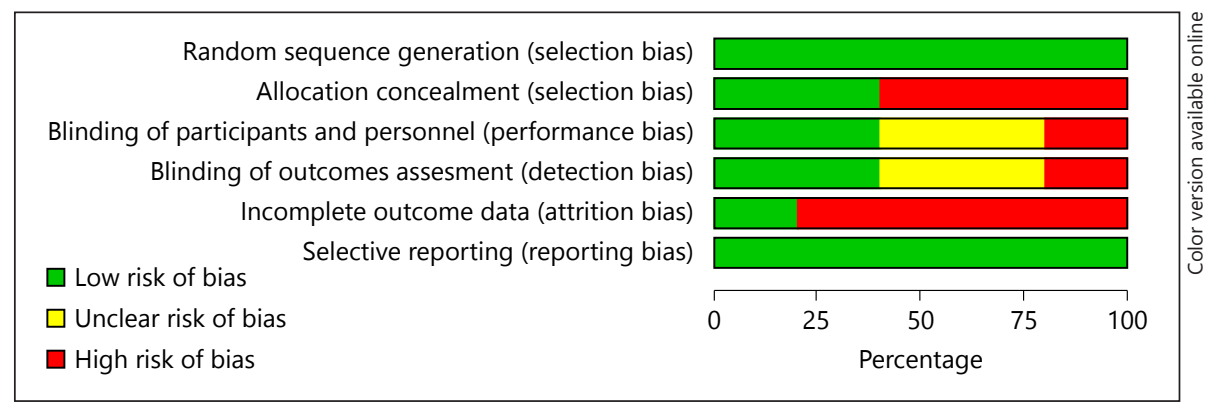

Incomplete Outcome Data (Attrition Bias)

In the study done by Asemi et al. [29], all allocated participants completed the study, so the attrition bias was rate low. The other study [30-33] were exposed to the high risk of attrition bias due to the use of drops.

Selective Reporting (Reporting Bias)

The reporting bias was rated low in all studies [29-33] because the primary and desired outcomes were reported (Table 1; Fig. 2, 3).

\section{Data Extraction}

The 3 reviewers (N.D., A.F.-K., and S.K.S.) extracted the data from all eligible studies and made an abstract of all information in an electronic form designed for this review; it contained the following elements: Author name, region, study design, study name, publication year, intervention, number of subjects, inclusion and exclusion criteria, primary endpoint, secondary endpoint, results, baseline differences, conclusion, and efficacy. The 2 reviewers resolved any disagreement in the same way as for screening by consultation with the fourth author (F.J.).

\section{The Outcome Measures}

The studies that met inclusion criteria [29-34] were reviewed by the fourth author (F.J.) and the outcomes of these RCTs that could be retained for meta-analysis were considered the primary outcome in this review. Therefore, the primary outcome measures included in this review were mean changes in FPG, Insulin, HOMA-IR, TG, TC, HDL cholesterol, LDL cholesterol, and hs-CRP. The secondary outcome measures were Newborns' hypoglycemia and hyperbilirubinemia.

\section{Data Synthesis and Analysis}

We used Statistical Review Manager 5.3 Software (RevMan; The Cochrane Collaboration, Oxford, UK) to perform the analysis. The result of the intention-to-treat analysis was obtained for all included studies whenever possible. Otherwise, we used available data (e.g., only per-protocol analysis results have been reported). The mean and SDs were obtained for all continuous outcomes. Where these were not available, they were calculated from other central tendency and dispersion measures (i.e., median and interquartile range) reported in the articles [35].

For the study by Asemi et al. [29], the results of hs-CRP were expressed by its mean and SD as ng/mL. However, the other studies expressed it as $\mathrm{mg} / \mathrm{L}$. For the purpose of unifying the measurement units in this review, the hs-CRP values in the Asemi et al. [29] were divided by 1,000 .

Maternal and Neonatal Metabolic

Outcomes of Vitamin D Supplementation

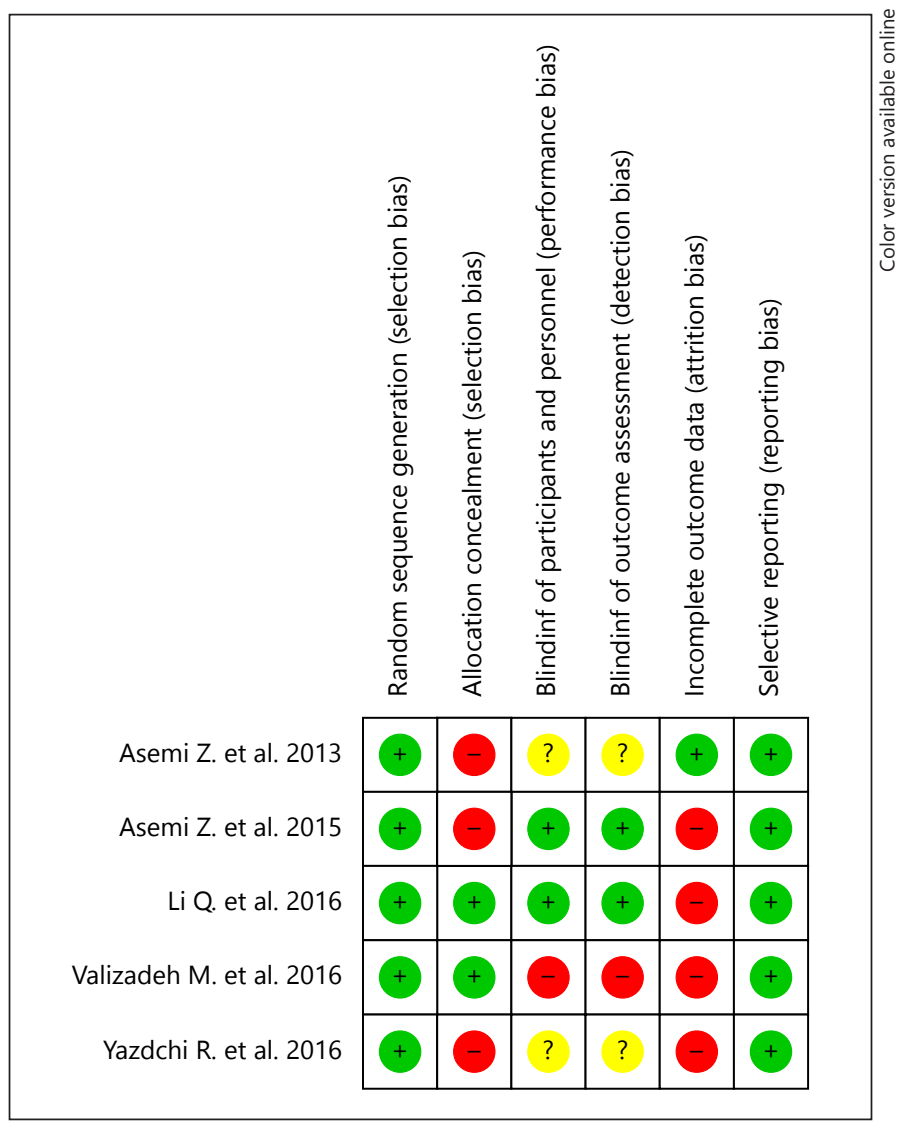

Fig. 3. Diagram of bias in the included studies.

The pooled estimate of treatment effect for binary (dichotomous) variables, such as newborn hyperglycemia, was calculated using OR with corresponding 95\% CIs. In the case of existing zero cell entries, instead of OR, the risk difference (RD) was used as a measure of treatment effect in meta-analysis. For continuous variables, such as FPG, the mean difference (MD) with 95\% CIs was used to calculate the treatment effect.

The mean changes and SDs of changes for all continuous variables were used for calculating MDs with 95\% CIs. For the studies that reported only the means and SDs for the baseline and follow-up measurements for each group, the means and SDs for change in the outcome were calculated for the study groups. We defined mean 
changes for each continuous outcome as measurement at the followup period minus measurement at baseline (follow up measurementbaseline measurement). SD for the change score was calculated as:

$$
\mathrm{SD}_{\text {change score }}=\sqrt{\mathrm{SD}_{\mathrm{b}}^{2}+\mathrm{SD}_{\mathrm{f}}^{2}+2 * \mathrm{r} * \mathrm{SD}_{\mathrm{b}} * \mathrm{SD}_{\mathrm{f}}}
$$

where $\mathrm{SD}_{\mathrm{b}}$ is the $\mathrm{SD}$ at baseline, $\mathrm{SD}_{\mathrm{f}}$ is the $\mathrm{SD}$ at follow-up and $\mathrm{r}$ is the correlation between baseline and the follow-up score [36]. The statistical results for heterogeneity across trials were assessed using the $I^{2}$ test, which represents the percentage of variability due to between-study variability, and the studies were considered heterogeneous if the value of $I^{2}$ was greater than $50 \%$. We presented the results of trials as random effect meta-analysis if the detected heterogeneity was significant. Otherwise, for minimal heterogeneity, a fixed-effect model was used. Forest plot was used to illustrate the result of this study.

\section{Results}

\section{Literature Search}

Figure 1 shows the search details of the study selection process and the reasons for exclusion of studies for our systematic review and meta-analysis of vitamin D supplementation in GDM. In total, 6 RCTs [29-34] met the inclusion criteria and their full texts were obtained for further review. Upon further scrutiny, 1 of these 6 RCTS, which did not include original data and had less relevant maternal outcomes [34], was excluded from the meta-analysis.

\section{Selected Articles}

By searching the databases, 7,835 articles were identified; of these, 711 were excluded as duplicates and 7,124 were screened for inclusion. Then, 6,729 were excluded by title and 440 articles excluded by abstract based on not being RCTs or quasi experimental studies, or using vitamin D supplementation for preventing GDM, or being conducted on T1DM or T2DM or on animals, or the intervention was not only vitamin D. Finally, out of 19 articles, 14 were excluded for not investigating the intended outcomes (the effect of vitamin D on the maternal and neonatal health measures). Finally, 5 articles were included in the meta-analysis (Fig. 1).

\section{Description of Studies}

The included trials in this systematic review were a full report published from 2013 to 2017 . All papers were written in English. All 5 studies were randomized and had a parallel study design. For the included studies, the number of participants was 54 [29], 45 [30], 42 [31], 97 [32], and 72 [33]. The total number of participants included in this systematic review was 310 . Four studies were conducted in Iran [29-31, 33], while the other one was conducted in China [32]. There was considerable clinical and methodological heterogeneity among trials with respect to supplement dose and study length. Mean baseline serum 25-hydroxy vitamin D levels were reported for all studies, all of which were in a deficient limit [37]. Furthermore, the dose, administration route, dosing interval, and duration of vitamin D supplementation were variable among almost of the studies as follows: 6 weeks with 50,000 IU vitamin D3, 2 times during the study (at baseline and at day 21 of the intervention) [29,30], 12 weeks with 200,000 IU vitamin D3 for each of the first 2 days, and then 50,000 IU per week thereafter, up to 700,000 IU in total. Those at week 28 of gestation or later were asked to take 100,000 IU weekly [31]. Sixteen weeks of yogurt drink supplemented with 500 IU vitamin D3 [32], and finally 8 weeks with 50,000 IU of vitamin D3 once every 2 weeks [33]. The details of these studies are summarized in Table 2, 3 .

\section{Risk of Bias in Included Studies}

The methodological quality according to the researchers' decisions on each risk of bias point for each included studies is shown in Figures 2 and 3.

\section{Efficacy of the Intervention}

Effect of Vitamin D Supplementation versus

Placebo on FPG

Three RCTs [29, 32, 33] with 223 participants studied the effect of vitamin D supplementation versus placebo on FPG serum level. As the $I^{2}$ statistic indicated, no heterogeneity was observed among the studies $\left(I^{2}=0 \%, p=\right.$ 0.46 ) and a fixed effect model was used to pool the data. The estimated overall effect demonstrated a statistically significant difference in the FPG serum level in women taking vitamin $\mathrm{D}$ supplements, meaning that intake of vitamin D supplements in women with GDM led to a significant lower FPG serum level (MD - $12.54 \mathrm{mg} / \mathrm{dL}$, 95\% CI -15.03 to $-10.05, p<0.001$; Fig. $4 a$ ).

\section{Effect of Vitamin D Supplementation on Insulin}

Three RCTs [29, 32, 33] with 223 participants studied the effect of vitamin D supplementation versus placebo on fasting plasma insulin serum level. As the $I^{2}$ statistic indicated considerable heterogeneity among the studies $\left(I^{2}=92 \%, p<0.001\right)$, a random effect model was used to pool the data. The estimated overall effect demonstrated that the differences between 2 groups was not statistically significant $(\mathrm{MD}-3.79 \mu \mathrm{IU} / \mathrm{ml}, 95 \% \mathrm{CI}-8.88$ to $1.30, p=$ 0.14; Fig. 4b). 


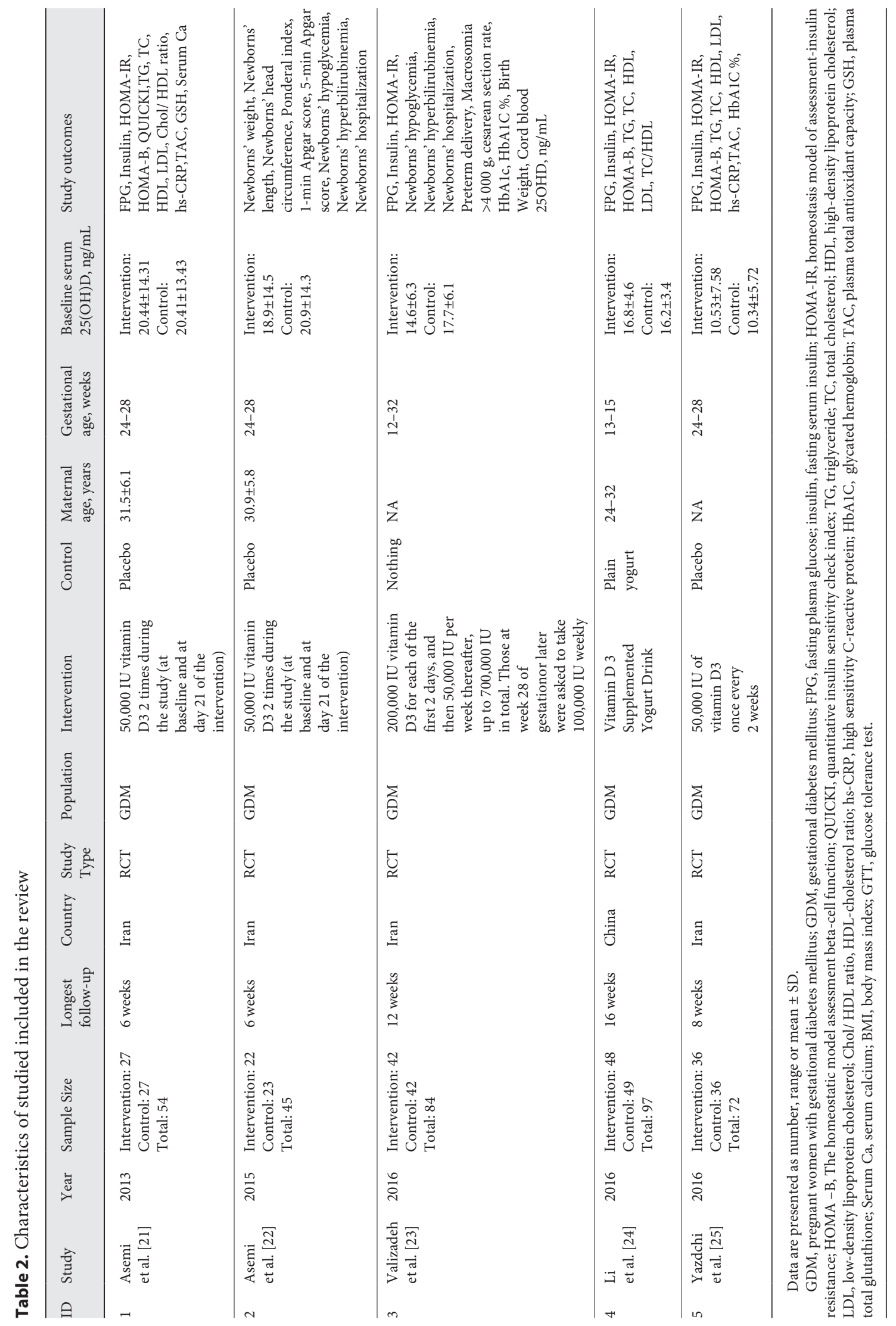




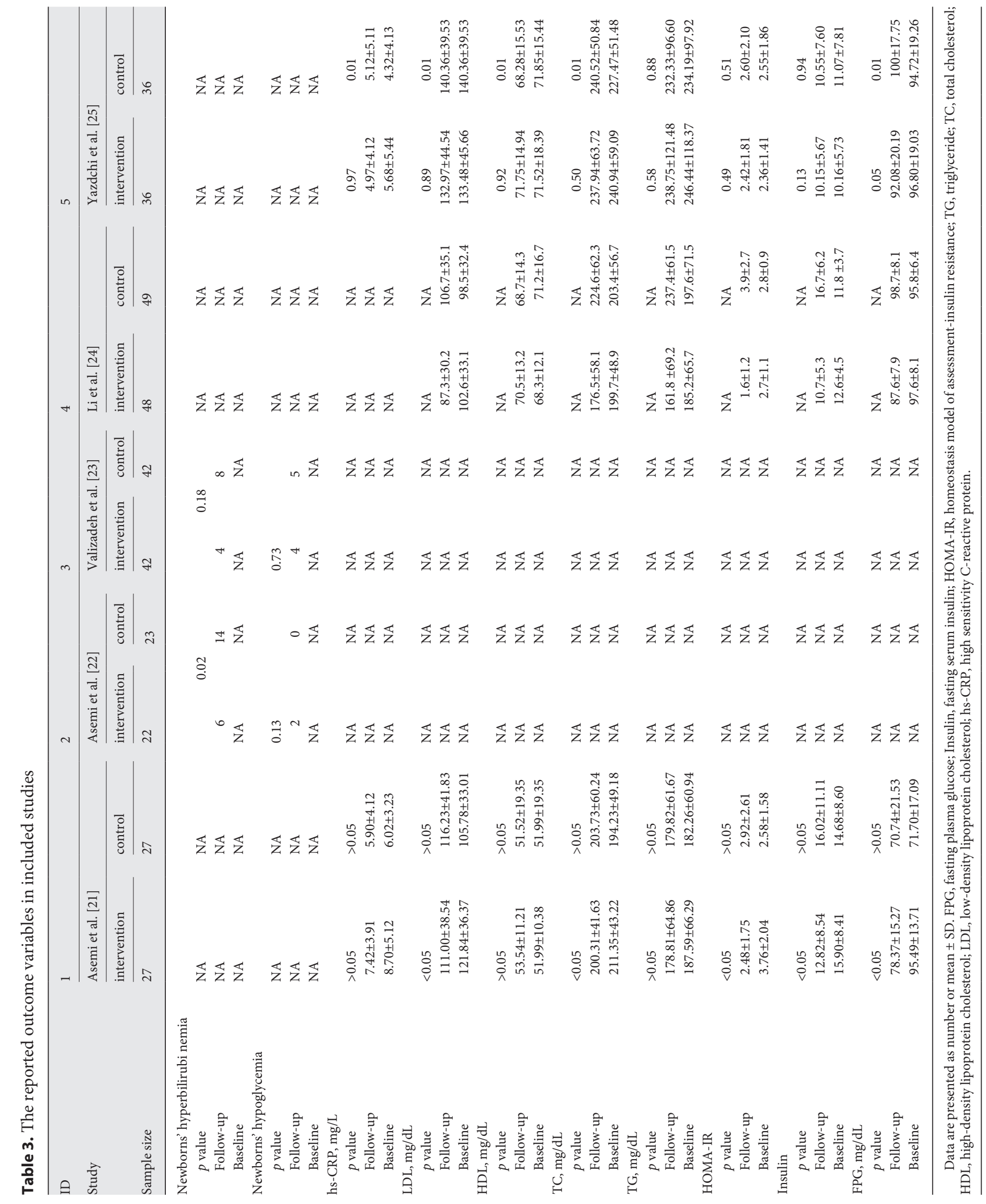




\begin{tabular}{|c|c|c|c|c|c|c|c|c|c|c|c|c|c|c|}
\hline Outcomes: FPG & \multicolumn{2}{|c|}{ Vitamin D } & \multicolumn{4}{|c|}{ Placebo } & \multicolumn{3}{|c|}{ Mean difference } & \multirow{2}{*}{\multicolumn{5}{|c|}{$\begin{array}{l}\text { Mean difference } \\
\text { IV, fixed, } 95 \% \mathrm{Cl}\end{array}$}} \\
\hline Study or subgroup & Mean & SD & Total & Mean & SD & Total & Weight & IV, fixed, 95\% Cl & Year & & & & & \\
\hline Asemi et al., 2013 & -17.12 & 14.84 & 27 & -0.96 & 16.64 & 27 & $8.8 \%$ & $-16.16[-24.57,-7.75]$ & 2013 & & & & & \\
\hline Li et al., 2016 & -9.9 & 7.2 & 48 & 2.9 & 7.6 & 49 & $71.5 \%$ & $-12.80[-15.75,-9.85]$ & 2013 & & - & & & \\
\hline Yazdchi R. et al., 2016 & -4.72 & 13.99 & 36 & 5.27 & 9.93 & 36 & $19.7 \%$ & $-9.99[-15.59,-4.39]$ & 2016 & & & & & \\
\hline Total $(95 \% \mathrm{Cl})$ & & & 111 & & & 112 & $100.0 \%$ & $-12.54[-15.03,-10.05]$ & & & & & & \\
\hline $\begin{array}{l}\text { Heterogeneity: } \mathrm{Chi}^{2}= \\
\text { Test for overall effect: }\end{array}$ & $\begin{array}{l}=1.54, \mathrm{df} \\
\mathrm{Z}=9.87\end{array}$ & $\begin{array}{l}=2(p \\
7(p<0 .\end{array}$ & $\begin{array}{l}=0.46) \\
.00001\end{array}$ & $; R^{2}=0$ & & & & & & -20 & -10 & 0 & 10 & 20 \\
\hline $\mathbf{a}$ & & & & & & & & & & Favou & vitam & D & ours pl & cebo \\
\hline
\end{tabular}

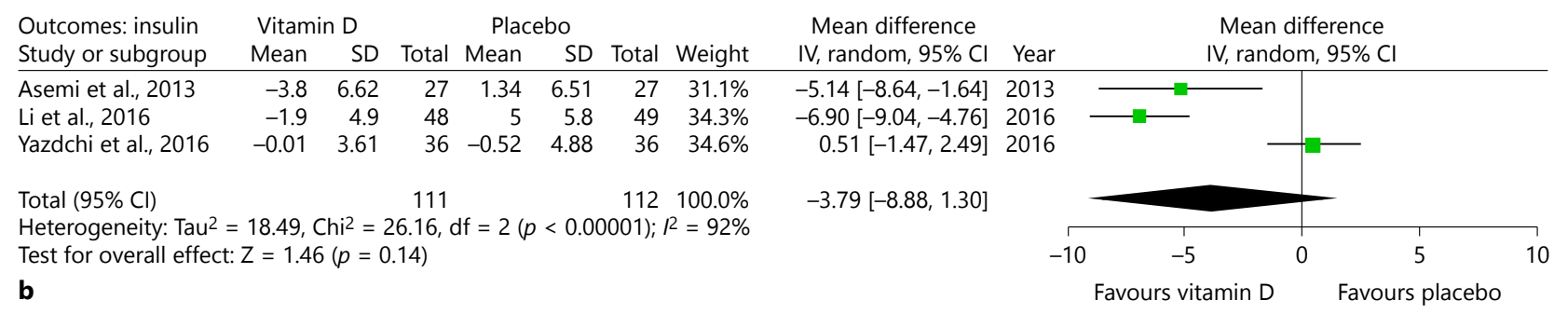

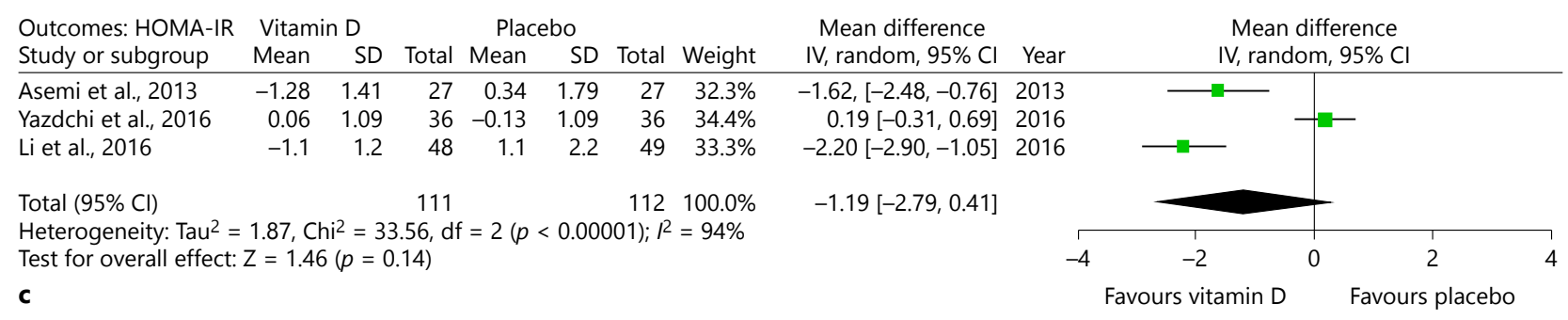

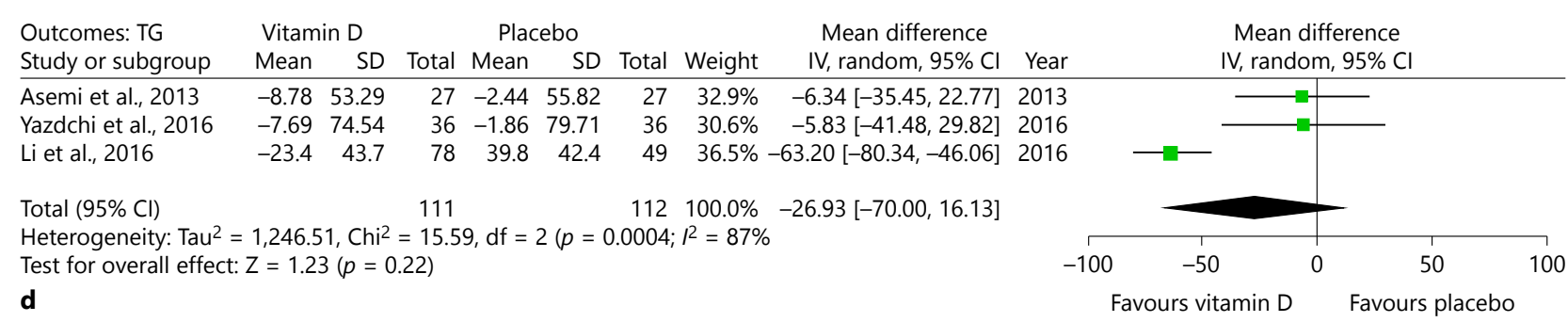

\begin{tabular}{|c|c|c|c|c|c|c|c|c|c|c|c|c|c|c|}
\hline \multirow{2}{*}{$\begin{array}{l}\text { Outcomes: TC } \\
\text { Study or subgroup }\end{array}$} & \multicolumn{2}{|c|}{ Vitamin D } & \multicolumn{4}{|c|}{ Placebo } & \multicolumn{3}{|c|}{ Mean difference } & \multirow{2}{*}{\multicolumn{5}{|c|}{$\begin{array}{l}\text { Mean difference } \\
\text { IV, fixed, } 95 \% \mathrm{CI}\end{array}$}} \\
\hline & Mean & SD & Total & Mean & SD & Total & Weight & IV, fixed, 95\% Cl & Year & & & & & \\
\hline Asemi et al., 2013 & -11.04 & 23.58 & 27 & 9.5 & 36.55 & 27 & $22.6 \%$ & $-20.54[-36.95,-4.13]$ & 2013 & & & & & \\
\hline Yazdchi et al., 2016 & -3 & 26.9 & 36 & 13.05 & 20.25 & 36 & $50.2 \%$ & $-16.05[-27.05,-5.05]$ & 2016 & & & & & \\
\hline Li et al., 2016 & -23.2 & 37.8 & 48 & 21.2 & 37.3 & 49 & $27.2 \%$ & $-44.40[-59.35,-29.45]$ & 2016 & $\longrightarrow$ & & & & \\
\hline \multirow{2}{*}{\multicolumn{10}{|c|}{$\begin{array}{l}\text { Total }(95 \% \mathrm{Cl}) \\
\text { Heterogeneity: } \mathrm{Chi}^{2}=9.30, \mathrm{df}=2(p=0.011) ; l^{2}=78 \% \\
\text { Test for overall effect: } \mathrm{Z}=6.23(p<0.00001)\end{array}$}} & & & & & \\
\hline & & & & & & & & & & -50 & -25 & 0 & 25 & 50 \\
\hline \multicolumn{10}{|l|}{ e } & Fav & s vi & & urs $p$ & \\
\hline
\end{tabular}

Fig. 4. Meta-analysis of maternal and neonatal health outcomes of vitamin D in and GDM. a Effect of vitamin D supplementation on FPG; (b) effect of vitamin D supplementation on Insulin; (c) effect of vitamin D supplementation on HOMA-IR; (d) effect of vitamin D supplementation on TG; (e) effect of vitamin D supplementa- tion on TC; (f) effect of vitamin D supplementation on LDL; (g) effect of vitamin D supplementation on HDL; (h) effect of vitamin D supplementation on hs-CRP; (i) effect of vitamin D supplementation on newborns' hypoglycemia; (j) effect of vitamin D supplementation on newborns' hyperbilirubinemi.

(For figure $4 f-j$ see next page.)
Maternal and Neonatal Metabolic

Outcomes of Vitamin D Supplementation 


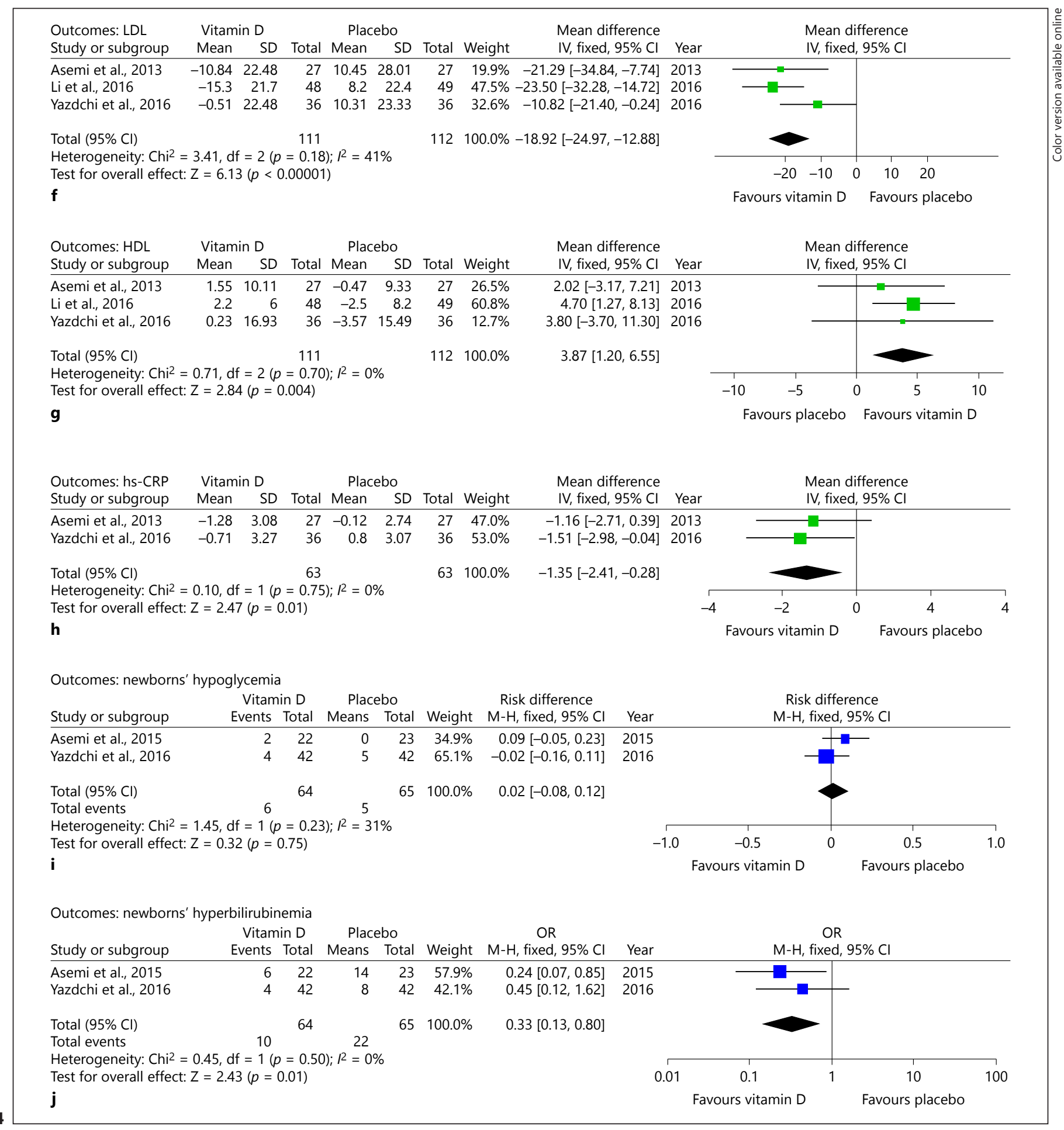

Effect of Vitamin D Supplementation on HOMA-IR

Three RCTs $[29,32,33]$ with 223 participants, studied the effect of vitamin D supplementation versus placebo on HOMA-IR serum level. As the $I^{2}$ statistic indicated considerable heterogeneity among the studies $\left(I^{2}=94 \%, p<\right.$
0.001), a random effect model was used to pool the data. The estimated overall effect demonstrated that the differences between 2 groups were not statistically significant (MD $-1.19,95 \% \mathrm{CI}-2.79$ to $0.41, p=0.14$; Fig. $4 \mathrm{c}$ ). 
Effect of Vitamin D Supplementation on TG

Three RCTs [29, 32, 33] with 223 participants studied the effect of vitamin D supplementation versus placebo on TG serum level. As the $I^{2}$ statistic indicated considerable heterogeneity among the studies $\left(I^{2}=87 \%, p<\right.$ 0.001 ), a random effect model was used to pool the data. The estimated overall effect demonstrated that the differences between 2 groups were not statistically significant (MD $-26.93 \mathrm{mg} / \mathrm{dL}, 95 \% \mathrm{CI}-70.00$ to $16.13, p=0.22$; Fig. 4d).

Effect of Vitamin D Supplementation on TC

Three RCTs $[29,32,33]$ with 223 participants studied the effect of vitamin D supplementation versus placebo on TC serum level. As the $I^{2}$ statistic indicated substantial heterogeneity among the studies $\left(I^{2}=78 \%, p=0.01\right)$, a fixed effect model was used to pool the data. The estimated overall effect demonstrated a statistically significant difference in the TC serum level in women taking vitamin $\mathrm{D}$ supplements, meaning that the intake of vitamin D supplements in women with GDM led to a significant lower TC serum level (MD -24.77 mg/dL, 95\% CI -32.57 to $-16.98, p<0.001$; Fig. $4 \mathrm{e})$.

Effect of Vitamin D Supplementation on LDL

Three RCTs [29, 32, 33] with 223 participants studied the effect of vitamin D supplementation versus placebo on the LDL cholesterol serum level. As the $I^{2}$ statistic indicated moderate heterogeneity among the studies $\left(I^{2}=\right.$ $41 \%, p=0.18$ ), a fixed effect model was used to pool the data. The estimated overall effect demonstrated a statistically significant difference in the LDL serum level in women taking vitamin $\mathrm{D}$ supplements, meaning that the intake of vitamin D supplements in women with GDM led to a significant lower LDL serum level (MD $-18.92 \mathrm{mg} / \mathrm{dL}, 95 \%$ CI -24.97 to $-12.88, p<0.001$; Fig. 4f).

Effect of Vitamin D Supplementation on HDL

Three RCTs [29, 32, 33] with 223 participants studied the effect of vitamin D supplementation versus placebo on the HDL cholesterol serum level. As the $I^{2}$ statistic indicated no heterogeneity among the studies $\left(I^{2}=0 \%, p=\right.$ 0.70 ), a fixed effect model was used to pool the data. The estimated overall effect demonstrated a statistically significant difference in HDL serum level in women taking vitamin D supplements, meaning that the intake of vitamin D supplements in women with GDMled to a significant higher HDL serum level (= $3.87 \mathrm{mg} / \mathrm{dL}, 95 \%$ CI $1.20-6.55, p=$ 0.004; Fig. 4g).

Maternal and Neonatal Metabolic Outcomes of Vitamin D Supplementation
Effect of Vitamin D Supplementation on hs-CRP

Two RCTs $[29,33]$ with 126 participants studied the effect of vitamin D supplementation versus placebo on the hs-CRP serum level. As the $I^{2}$ statistic indicated no heterogeneity among the studies $\left(I^{2}=0 \%, p=0.75\right)$, a fixed effect model was used to pool the data. The estimated overall effect demonstrated a statistically significant difference in the hs-CRP serum level in women taking vitamin $\mathrm{D}$ supplements, meaning that the intake of vitamin D supplements in women with GDM led to a significant lower hs-CRP serum level (MD $-1.35 \mathrm{mg} / \mathrm{L}, 95 \% \mathrm{CI}$ -2.41 to $-0.28, p=0.01$; Fig. $4 \mathrm{~h}$ ).

Effect of Vitamin D Supplementation on Newborns' Hypoglycemia

Two RCTs [30, 33] with 129 participants studied the effect of vitamin D supplementation versus placebo on newborns' hypoglycemia. As the $I^{2}$ statistic indicated moderate heterogeneity among the studies $\left(I^{2}=31 \%, p=\right.$ 0.23 ), a fixed effect model was used to pool the data. The estimated overall effect demonstrated no statistically significant association between taking vitamin $\mathrm{D}$ supplements and newborns' hypoglycemia (RD 0.02, 95\% CI -0.08 to $0.12, p=0.75$; Fig. $4 \mathrm{i}$ ).

\section{Effect of Vitamin D Supplementation on Newborns'}

Hyperbilirubinemia

Two RCTs [30, 33] with 129 participants, studied the effect of vitamin $\mathrm{D}$ supplementation versus placebo on newborns' hyperbilirubinemia. As the $I^{2}$ statistic indicated no heterogeneity among the studies $\left(I^{2}=0 \%, p=0.50\right)$, a fixed effect model was used to pool the data. The estimated overall effect demonstrated statistically significant association between taking vitamin $\mathrm{D}$ supplements and prevention of newborns' hyperbilirubinemia, meaning that newborn's in vitamin $\mathrm{D}$ group was less likely to develop hyperbilirubinemia than that in placebo group (OR $0.33,95 \%$ CI $0.13-0.80, p=0.01$; Fig. $4 \mathrm{j}$ ).

\section{Discussion}

This systematic review and meta-analysis evaluated the therapeutic and pure effect of vitamin D supplementation on glycemic control, lipid profiles, inflammatory indices, and newborns' hypoglycemia and hyperbilirubinemia in patients with GDM. Therefore, the studies assessed the effect of vitamin $\mathrm{D}$ in combination with other treatments or those evaluated the preventive effects of vitamin D supplements were not included.

Ann Nutr Metab 2018;73:145-159 
This meta-analysis demonstrated that vitamin D supplementation may lead to an improvement in FPG, TC, LDL, HDL serum level, and hs-CRP serum levels but did not affect insulin and TG serum levels and HOMA-IR. About newborns' outcomes, vitamin D supplementation may prevent newborns' hyperbilirubinemia; however, there was no statistically significant association between taking vitamin D supplements and newborns' hypoglycemia.

GDM has adverse outcomes for the health of the mother and the neonatal [38] and there is an obvious requirement for safe, low-cost remedies to help in the prevention and management of it.

Vitamin D remains to gather extensive consideration from clinicians, researchers, and the community. The Institute of Medicine determines that a serum 25(OH)D concentration less than $30 \mathrm{nmol} / \mathrm{L}$ is vitamin $\mathrm{D}$ deficiency [39], whereas the Endocrine Society states vitamin D deficiency as $25(\mathrm{OH}) \mathrm{D}$ less than $50 \mathrm{nmol} / \mathrm{L}$ [40]. The estimated average intake requirement for bone health for adult women during pregnancy is specified as $400 \mathrm{IU} /$ day by government agencies representing North America [41] and the United Kingdom [42, 43].

In Iran, various studies have been conducted on the prevalence of vitamin D deficiency in pregnant women, and their outcomes are different $[44,45]$. The mean concentration of vitamin D in Iranian pregnant women has been reported to be $13.68-16.35 \mathrm{ng} / \mathrm{mL}$ [46] and it signifies a prevalent public health issue in Iran [47]. According to the results of a recent systematic review and meta-analysis performed by Azami et al. [46], the prevalence of vitamin $\mathrm{D}$ deficiency during pregnancy based on the cutting point of $10 \mathrm{ng} / \mathrm{mL}$, is $41.9 \%$ in Iranian population; this is higher compared with the prevalence provided in America and Oceania regions. On the other hand, vitamin $\mathrm{D}$ deficiency (25-hydroxyvitamin $\mathrm{D}<20 \mathrm{ng} / \mathrm{mL}$ ) was established to be highly prevalent among pregnant Chinese women, which one of the studies included in this systematic review, and meta-analyses were conducted in China [48].

Meta-analysis of individual patient level data for non-skeletal outcomes showed that the benefit of vitamin D supplementation is seen in those with $25 \mathrm{OHD}$ below $25 \mathrm{nmol} / \mathrm{L}$ and is less likely in those on mega intermittent doses $[49,50]$. High-dose vitamin D does not prevent diabetes [51].

The results of our study are clinically significant because they demonstrate the potential of vitamin D supplementation to help in significantly reducing fasting blood glucose levels. Vitamin D supplementation did not improve insulin level and HOMA-IR significantly; how- ever, there was considerable heterogeneity among the studies.

Zhang et al. [24] in a recent systematic review of observational studies and RCTs showed that low blood level of $25(\mathrm{OH}) \mathrm{D}$ during pregnancy was related with a higher risk of GDM. Similar to our results, vitamin D supplementation could reduce FPG level but also HOMA-IR during pregnancy. According to our results, insulin and HOMA-IR decrease because vitamin D supplementation was not statistically significant.

Based on the results of systematic review, meta-analysis was performed by Akbari et al. [25]; vitamin D supplementation significantly reduced HOMA-IR and HOMA$\mathrm{B}$ and significantly increased QUICKI. This difference is probably because of different inclusion and exclusion criteria of this study so that we excluded the studies that vitamin D administered combined with other nutrients or postpartum administration. Some possible effects of vitamin D associated with glucose metabolism are [52]: (1) the straight function of vitamin $\mathrm{D}$ on the pancreatic $\beta$-cell operation, which happens through the expression of the receptor of vitamin $D$ as well as the 25-hydroxyvitamin $\mathrm{D}$-1- $\alpha$-hydroxylase enzyme in the pancreatic $\beta$-cells; (2) the effect of vitamin $\mathrm{D}$ on insulin resistance through the modification of intracellular calcium, which impacts the transport of glucose in target tissues, and (3) the impact of vitamin D on systemic inflammation related to insulin resistance in diabetes mellitus.

Current evidences propose that vitamin D deficiency may contribute to undesirable cardio-metabolic presentations during pregnancy and unfavorable pregnancy consequences [53, 54]. Changed lipid metabolism of the mother is usual in pregnancy with mild increment in lipids early in pregnancy and considerable raises of lipids advanced in pregnancy, specifically, TG and to a slighter degree cholesterol $[55,56]$. In women with GDM, the physiological variations in insulin and lipids are overstated and may show fundamental metabolic disorders that briefly show up during pregnancy [57].

Observational studies have established that high serum $25(\mathrm{OH}) \mathrm{D}$ levels were correlated with a promising consequence on the lipid profile. Mousa et al. [58] in a cross-sectional study discovered inverse correlations between $25(\mathrm{OH}) \mathrm{D}$ serum levels and total serum cholesterol and TG levels at 12-15 weeks of pregnancy. However, Al-Ajlan et al. [36] found that 25(OH)D serum levels in the first trimester of gestation were positively correlated with lipid concentrations, which was supposed to be due to the higher biosynthesis of lipid in reaction to increased metabolic requirements in early pregnancy [59]. 
According to the results of our meta-analysis, vitamin D supplementation may lead to an improvement in TC, LDL, and HDL serum level but not TG. Along with our study, a systematic review done by Zhang et al. [24] showed that vitamin $\mathrm{D}$ supplementation during pregnancy could significantly elevate HDL concentration and reduce blood TC and LDL concentration.

From the perspective of mechanism, vitamin D may work via the vitamin $\mathrm{D}$ receptor to inhibit foam cell development [60], decrease uptake of acetylated LDL cholesterol [61] and normalize apolipoprotein A-1 serum levels [62], so improving cholesterol transport and enhancing lipid profiles [61-63]. Vitamin D can also improve insulin resistance and GDM risk by downregulating proinflammatory cytokines and upregulating anti-inflammatory cytokines [64-66]. According to the result of this study, vitamin D supplementation leads to an improvement in hs-CRP serum levels. Inflammatory processes are considered to be the lost chain loop between GDM and multiple sclerosis, which is connected to insulin resistance [67]. An increased level of C-reactive protein (CRP) is supposed to persuade chronic inflammation, and also the levels of uric acid, an index for the risk of CVD and T2DM. The impact of vitamin D3 supplementation on CRP levels, the most usually stated index of inflammation, is controversial. Amer et al. [68] stated that $25(\mathrm{OH}) \mathrm{D}$ serum levels $<21 \mathrm{ng} / \mathrm{mL}(<52.42 \mathrm{nmol} / \mathrm{L})$ have an inverse relation with CRP levels among healthy adults in the United States, whereas CRP levels $\geq 21 \mathrm{ng} / \mathrm{mL}$ have a positive relation. Numerous studies have detected vitamin D (calcitriol) ability to prevent construction and expression of inflammatory cytokines [69-72]. Vitamin D and its active form have been revealed to decrease lipopolysaccharide-induced tumor necrosis factor alpha production, and additionally known to control the action of nuclear factor $\kappa \mathrm{B}$, which intercedes the proinflammtory actions of tumor necrosis factor alpha $[69,70,73]$.

\section{Strengths and Limitations}

This systematic review and meta-analysis were done by a thorough and sensitive search strategy with the cooperation of a research librarian. This study focused on the effect of vitamin D supplements on women with gestational diabetes, and therefore, studies that investigated its effect on preventing gestational diabetes were not included in the study.

Main limitations of this study are the high degree of heterogeneity among included studies and the quite short intervention duration and little sample size of studies, which may restrict our capability to extract inferences on

Maternal and Neonatal Metabolic

Outcomes of Vitamin D Supplementation the effects of long-term vitamin D supplementation. Due to the limited number of included studies in this metaanalysis, we could not perform sub-group analysis based on the received supplemental dosage. Therefore, subgroup analysis in this regard is suggested in future review studies. In addition, our systematic review and metaanalysis are not generalizable to pregnant subjects with normal glucose metabolism or with normal $25(\mathrm{OH}) \mathrm{D}$ serum levels. This meta-analysis may be an issue to publication bias, where null results of unpublished clinical trials lead to unrepresentativeness of intervention effects in the published texts.

\section{Conclusion}

In conclusion, this systematic review and meta-analysis demonstrate that the supplementation of GDM women with vitamin D may lead to improvement in FPG, TC, LDL, HDL, and hs-CRP serum levels as well as newborns' hyperbilirubinemia, but did not affectInsulin and TG serum levels, HOMA-IR, and Newborns' hypoglycemia. However, the potential benefit is evident regardless of dose. Considering the low serum level of $25(\mathrm{OH}) \mathrm{D}$ in women in the included studies, it is possible that these women benefit more from vitamin D supplements. Therefore, it seems that investigating Reference Daily Intake (RDI) of vitamin D for these women during pregnancy through further studies is necessary. This is particularly important because management of gestational diabetes with medications, such as metformin, is intricate by the hazards related to trans-placental transmission and probable detrimental impacts on fetal evolvement and/or upcoming neonate well-being.

\section{Acknowledgment}

We thank the technical staff at physical medicine and rehabilitation research center of Tabriz University of Medical Sciences for their invaluable assistance with this study. None of the authors reported a conflict of interest related to the study. This study was supported financially by the physical medicine and rehabilitation research center. The funders had no role in the study design, data collection, and analysis, decision to publish, or preparation of the manuscript.

\section{Funding Source}

This research did not receive any specific grant from funding agencies in the public, commercial, or not-for-profit sectors. 


\section{References}

1 Alberti KG, Zimmet P, Shaw J: International diabetes federation: a consensus on type 2 diabetes prevention. Diabet Med 2007;24:451463.

2 Committee on Practice Bulletins - Obstetrics: Practice bulletin no. 137: gestational diabetes mellitus. Obstet Gynecol 2013;122:406-416.

3 Donazar-Ezcurra M, Lopez-Del Burgo C, Bes-Rastrollo M: Primary prevention of gestational diabetes mellitus through nutritional factors: a systematic review. BMC Pregnancy Childbirth 2017;17:30.

4 Hajifaraji M, Dolatkhah N: Gestational diabetes mellitus and associated challenges from the perspective of nutrition science: a review article. J Mazandaran Univ Med Sci 2017;27: 202-224.

5 Klein S, Sheard NF, Pi-Sunyer X, Daly A, Wylie-Rosett J, Kulkarni K, et al: Weight management through lifestyle modification for the prevention and management of type 2 diabetes: rationale and strategies. Diabet Care 2004; 27:2067-2073.

6 Williams R, Van Gaal L, Lucioni C: Assessing the impact of complications on the costs of type II diabetes. Diabetologia 2002;45:S13S17.

7 Bruce SP, Acheampong F, Kretchy I: Adherence to oral anti-diabetic drugs among patients attending a Ghanaian teaching hospital. Pharm Prac 2015;13:533.

8 Dolatkhah N, Hajifaraji M, Abbasalizadeh F, Aghamohammadzadeh N, Mehrabi Y, Abbasi MM: Is there a value for probiotic supplements in gestational diabetes mellitus? A randomized clinical trial. J Health Popul Nutr 2015;33:25.

9 Hajifaraji M, Jahanjou F, Abbasalizadeh F, Aghamohammadzadeh N, Abbasi MM, Dolatkhah N: Effect of probiotic supplementation on blood pressure of females with gestational diabetes mellitus: a randomized double blind controlled clinical trial. Iranian Red Crescent Med J 2017;19:e55662.

10 Hajifaraji M, Jahanjou F, Abbasalizadeh F, Aghamohammadzadeh N, Abbasi MM, Dolatkhah N. Effect of probiotic supplements in women with gestational diabetes mellitus on inflammation and oxidative stress biomarkers: a randomized clinical trial. Asia Pacific J Clin Nutr 2018;27:581.

11 Facchinetti F, Dante G, Petrella E, Neri I: Dietary interventions, lifestyle changes, and dietary supplements in preventing gestational diabetes mellitus: a literature review. Obstet Gynecol Surv 2014;69:669-680.

12 D’Anna R, Scilipoti A, Giordano D, Caruso C, Cannata ML, Interdonato ML, et al: Myo-Inositol supplementation and onset of gestational diabetes mellitus in pregnant women with a family history of type 2 diabetes: a prospective, randomized, placebo-controlled study. Diabet Care 2013;36:854-857.

13 Adela R, Borkar RM, Bhandi MM, Vishwakarma G, Reddy PN, Srinivas R, et al: Lower vitamin D metabolites levels were associated with increased coronary artery diseases in type 2 diabetes patients in india. Sci Rep 2016; 6:37593.

14 Talaei A, Mohamadi M, Adgi Z: The effect of vitamin $\mathrm{D}$ on insulin resistance in patients with type 2 diabetes. Diabetol Metab Syndr 2013;5:8.

15 Mozos I, Marginean O: Links between vitamin D deficiency and cardiovascular diseases. Biomed Res Int 2015;2015:109275.

16 Lavie CJ, Lee JH, Milani RV: Vitamin D and cardiovascular disease will it live up to its hype? J Am Coll Cardiol 2011;58:1547-1556.

17 Tanaka Y, Seino Y, Ishida M, Yamaoka K, Yabuuchi $\mathrm{H}$, Ishida $\mathrm{H}$, et al: Effect of vitamin D3 on the pancreatic secretion of insulin and somatostatin. Acta Endocrinol (Copenh) 1984;105:528-533.

18 Chertow BS, Sivitz WI, Baranetsky NG, Clark SA, Waite A, Deluca HF: Cellular mechanisms of insulin release: the effects of vitamin D deficiency and repletion on rat insulin secretion. Endocrinology 1983;113: 1511-1518.

19 Maestro B, Molero S, Bajo S, Davila N, Calle C: Transcriptional activation of the human insulin receptor gene by 1,25-dihydroxyvitamin D(3). Cell Biochem Funct 2002;20:227232.

20 Morley R: Maternal 25-hydroxyvitamin D and parathyroid hormone concentrations and offspring birth size. J Clin Endocrinol Metab 2006;91:906-912.

21 Bowyer L, Catling-Paull C, Diamond T, Homer C, Davis G, Craig ME: Vitamin D, PTH and calcium levels in pregnant women and their neonates. Clin Endocrinol (Oxf) 2009; 70:372-377.

22 Shin JS, Choi MY, Longtine MS, Nelson DM: Vitamin D effects on pregnancy and the placenta. Placenta 2010;31:1027-1034

23 Palaniswamy S, Williams D, Järvelin MR, Sebert S: Vitamin D and the promotion of longterm metabolic health from a programming perspective. Nutr Metab Insights 2015;8(suppl 1):11.

24 Zhang Y, Gong Y, Xue H, Xiong J, Cheng G: Vitamin $\mathrm{D}$ and gestational diabetes mellitus: a systematic review based on data free of hawthorne effect. BJOG 2018;125:784-793.

25 Akbari M, Moosazadeh M Lankarani KB, Tabrizi R, Samimi M, Karamali M, et al: The effects of vitamin D supplementation on glucose metabolism and lipid profiles in patients with gestational diabetes: a systematic review and meta-analysis of randomized controlled trials. Horm Metab Res 2017;49:647-653.

26 Higgins JP, Green S: Cochrane Handbook for Systematic Reviews of Interventions. John Wiley \& Sons, 2011.

27 Moher D, Liberati A, Tetzlaff J, Altman DG: Preferred reporting items for systematic reviews and meta-analyses: the PRISMA statement. Ann Intern Med 2009;151:264-269, W64.
28 Phan K, Tian DH, Cao C, Black D, Yan TD: Systematic review and meta-analysis: techniques and a guide for the academic surgeon. Ann Cardiothorac Surg 2015;4:112-122.

29 Asemi Z, Hashemi T, Karamali M, Samimi M, Esmaillzadeh A: Effects of vitamin D supplementation on glucose metabolism, lipid concentrations, inflammation, and oxidative stress in gestational diabetes: a double-blind randomized controlled clinical trial. Am J Clin Nutr 2013;98:1425-1432.

30 Asemi Z, Karamali M, Esmaillzadeh A: Favorable effects of vitamin D supplementation on pregnancy outcomes in gestational diabetes: a double blind randomized controlled clinical trial. Horm Metab Res 2015;47:565-570.

31 Valizadeh M, Piri Z, Mohammadian F, Kamali K, Moghadami HR: The impact of vitamin D supplementation on post-partum glucose tolerance and insulin resistance in gestational diabetes: a randomized controlled trial. Int J Endocrinol Metab 2016;14:e34312.

32 Li Q, Xing B: Vitamin D3-supplemented yogurt drink improves insulin resistance and lipid profiles in women with gestational diabetes mellitus: a randomized double blinded clinical trial. AnnNutr Metab 2016;68:285-290.

33 Yazdchi R, Gargari BP, Asghari-Jafarabadi M, Sahhaf F: Effects of vitamin D supplementation on metabolic indices and hs-CRP levels in gestational diabetes mellitus patients: a randomized, double-blinded, placebo-controlled clinical trial. Nutr Res Pract 2016;10:328-335.

34 Zhang Q, Cheng Y, He M, Li T, Ma Z, Cheng $\mathrm{H}$ : Effect of various doses of vitamin D supplementation on pregnant women with gestational diabetes mellitus: a randomized controlled trial. Exp Ther Med 2016;12:18891895.

35 Wan X, Wang W, Liu J, Tong T: Estimating the sample mean and standard deviation from the sample size, median, range and/or interquartile range. BMC Med Res Methodo 2014; 14:135.

36 Fu R, Vandermeer BW, Shamliyan TA, O’Neil ME, Yazdi F, Fox SH, et al: Handling Continuous Outcomes In Quantitative Synthesis, 2013.

37 Kennel KA, Drake MT, Hurley DL: Vitamin D deficiency in adults: when to test and how to treat. Mayo Clin Proc 2010;85:752-757.

38 Leitner M, Fragner L, Danner S, Holeschofsky N, Leitner K, Tischler S, et al: Combined metabolomic analysis of plasma and urine reveals $\mathrm{AHBA}$, tryptophan and serotonin metabolism as potential risk factors in gestational diabetes mellitus (GDM). Front Mol Biosci 2017;4:84.

39 Institute of Medicine Committee to Review Dietary Reference Intakes for Vitamin D and Calcium; in Ross A, Taylor C, Yaktine A (eds): Dietary Reference Intakes for Calcium and Vitamin D. Washington, National Academies Press, 2011. 
40 Holick MF, Binkley NC, Bischoff-Ferrari HA, Gordon CM, Hanley DA, Heaney RP, et al: Evaluation, treatment, and prevention of vitamin D deficiency: an Endocrine Society clinical practice guideline. J Clin Endocrinol Metab 2011;96:1911-1930.

41 De-Regil LM, Palacios C, Lombardo LK, Pena-Rosas JP: Vitamin D supplementation for women during pregnancy. Cochrane Database Syst Rev 2016;6:CD008873.

42 Del Valle HB, Yaktine AL, Taylor CL, Ross AC: Dietary Reference Intakes for Calcium and Vitamin D. National Academies Press, 2011.

43 Crown PHE. Scientific Advisory Committee of Nutrition. Vitamin D and Health. 2016. https://www.gov.uk/government/groups/scientific-advisory-committee-on-nutrition (January 25, 2017).

44 ZahediAsl S, Eyni E: The Relationship between Calcium \& Vitamin D and Vitamins A and E in Pregnant Tehranian Women, 2004.

45 Kazemi A, Sharifi F, Jafari N, Mousavinasab $\mathrm{N}$ : High prevalence of vitamin $\mathrm{D}$ deficiency among pregnant women and their newborns in an Iranian population. J Womens Health 2009; 18:835-839.

46 Azami M, Badfar G, Shohani M, Mansouri A, Yektayekooshali M, Sharifi A, et al: Systematic review and meta-analysis of the mean concentration of vitamin $\mathrm{D}$ in pregnant and infants in Iran [persian]. Iranian J Obstet Gynecol Infertil 2017;20:76-87.

47 McAree T, Jacobs B, Manickavasagar T, Sivalokanathan S, Brennan L, Bassett P, et al: Vitamin D deficiency in pregnancy-still a public health issue. Matern Child Nutr 2013;9:2330.

48 Yun C, Chen J, He Y, Mao D, Wang R, Zhang $\mathrm{Y}$, et al: Vitamin d deficiency prevalence and risk factors among pregnant chinese women. Public Health Nutr 2017;20:1746-1754.

49 Jolliffe DA, Greenberg L, Hooper RL, Griffiths CJ, Camargo CA Jr, Kerley CP, et al: Vitamin D supplementation to prevent asthma exacerbations: a systematic review and meta-analysis of individual participant data. Lancet Respir Med 2017;5:881-890.

50 Martineau AR, Jolliffe DA, Hooper RL, Greenberg L, Aloia JF, Bergman P, et al: Vitamin D supplementation to prevent acute respiratory tract infections: systematic review and meta-analysis of individual participant data. BMJ 2017;356:i6583.

51 Jorde R, Sollid ST, Svartberg J, Schirmer H, Joakimsen RM, Njølstad I, et al: Vitamin D
20,000 IU per week for five years does not prevent progression from prediabetes to diabetes. J Clin Endocrinol Metab 2016;101:16471655.

52 Alvarez JA, Ashraf A: Role of vitamin D in insulin secretion and insulin sensitivity for glucose homeostasis. Int J Endocrinol 2010; 2010:351385.

53 Perez-Ferre N, Torrejon MJ, Fuentes M, Fernandez MD, Ramos A, Bordiu E, et al: Association of low serum 25-hydroxyvitamin D levels in pregnancy with glucose homeostasis and obstetric and newborn outcomes. Endocr Pract 2012;18:676-684.

54 Wei SQ, Qi HP, Luo ZC, Fraser WD: Maternal vitamin $D$ status and adverse pregnancy outcomes: a systematic review and meta-analysis. J Matern Fetal Neonatal Med 2013;26: 889-899.

55 Herrera E: Disturbances in lipid metabolism in diabetic pregnancy-are these the cause of the problem? Best Pract Res Clin Endocrinol Metab 2010;24:515-525.

56 Alvarez J, Montelongo A, Iglesias A, Lasuncion MA, Herrera E: Longitudinal study on lipoprotein profile, high density lipoprotein subclass, and postheparin lipases during gestation in women. J Lipid Res 1996;37:299-308.

57 Carpenter MW: Gestational diabetes, pregnancy hypertension, and late vascular disease. Diabet Care 2007;30(supp 2):S246-S250.

58 Mousa A, Abell SK, Shorakae S, Harrison CL, Naderpoor N, Hiam D, et al: Relationship between vitamin $\mathrm{D}$ and gestational diabetes in overweight or obese pregnant women may be mediated by adiponectin. Mol Nutr Food Res 2017;61.

59 Al-Ajlan A, Krishnaswamy S, Alokail MS, Aljohani NJ, Al-Serehi A, Sheshah E, et al: Vitamin $\mathrm{D}$ deficiency and dyslipidemia in early pregnancy. BMC Pregnancy Childbirth 2015; $15: 314$.

60 Oh J, Weng S, Felton SK, Bhandare S, Riek A, Butler B, et al: 1,25(OH)2 vitamin D inhibits foam cell formation and suppresses macrophage cholesterol uptake in patients with type 2 diabetes mellitus. Circulation 2009;120: 687-698.

61 Al-Daghri NM, Alkharfy KM, Al-Saleh Y, AlAttas OS, Alokail MS, Al-Othman A, et al: Modest reversal of metabolic syndrome manifestations with vitamin D status correction: a 12-month prospective study. Metabolism 2012;61:661-666.

62 Wehmeier KR, Mazza A, Hachem S, Ligaray $\mathrm{K}$, Mooradian AD, Wong NC, et al: Differ- ential regulation of apolipoprotein AI gene expression by vitamin $\mathrm{D}$ receptor modulators. Biochim Biophys Acta 2008;1780:264273.

63 Carbone LD, Rosenberg EW, Tolley EA, Holick MF, Hughes TA, Watsky MA, et al: 25-Hydroxyvitamin D, cholesterol, and ultraviolet irradiation. Metabolism 2008;57:741748 .

64 Giulietti A, van Etten E, Overbergh L, Stoffels K, Bouillon R, Mathieu C: Monocytes from type 2 diabetic patients have a pro-inflammatory profile: 1, 25-Dihydroxyvitamin D3 works as anti-inflammatory. Diabetes Res Clin Practice. 2007;77:47-57.

65 Korf H, Wenes M, Stijlemans B, Takiishi T, Robert S, Miani M, et al: 1,25-Dihydroxyvitamin D3 curtails the inflammatory and T cell stimulatory capacity of macrophages through an IL-10-dependent mechanism. Immunobiology 2012;217:1292-1300.

66 Zhang Y, Leung DY, Richers BN, Liu Y, Remigio LK, Riches DW, et al: Vitamin D inhibits monocyte/macrophage proinflammatory cytokine production by targeting MAPK phosphatase-1. J Immunol 2012;188:21272135.

67 Kahn BB, Flier JS: Obesity and insulin resistance. J Clin Invest 2000;106:473-481.

68 Amer M, Qayyum R: Relation between serum 25-hydroxyvitamin D and C-reactive protein in asymptomatic adults (from the continuous National Health and Nutrition Examination Survey 2001 to 2006). Am J Cardiol 2012;109: 226-230.

69 Ding C, Gao D, Wilding J, Trayhurn P, Bing C: Vitamin D signalling in adipose tissue. $\mathrm{Br}$ J Nutr 2012;108:1915-1923.

70 Teegarden D, Donkin SS: Vitamin D: emerging new roles in insulin sensitivity. Nutr Res Rev 2009;22:82-92.

71 Guillot X, Semerano L, SaidenbergKermanac'h N, Falgarone G, Boissier MC: Vitamin $\mathrm{D}$ and inflammation. Joint Bone Spine 2010;77:552-557.

72 Almerighi C, Sinistro A, Cavazza A, Ciaprini C, Rocchi G, Bergamini A: 1Alpha,25-dihydroxyvitamin D3 inhibits CD40L-induced pro-inflammatory and immunomodulatory activity in human monocytes. Cytokine 2009; 45:190-197.

73 Ding C, Wilding JP, Bing C: 1,25-dihydroxyvitamin D3 protects against macrophage-induced activation of NFkappaB and MAPK signalling and chemokine release in human adipocytes. PLoS One 2013;8:e61707.
Maternal and Neonatal Metabolic

Outcomes of Vitamin D Supplementation
Ann Nutr Metab 2018;73:145-159 